\title{
Influence of Waste Polypropylene Fibers on Resilient Modulus of Clay Soil
}

\author{
Rohin Kaushik ${ }^{1,}$ Tarun Sharma ${ }^{2 *}$ \\ ${ }^{1}$ Assistant Professor, Department of Civil Engineering, DAV University, Jalandhar-144012; e-mail: \\ rohin.pb10@gmail.com \\ ${ }^{2 *}$ Assistant Professor, Department of Civil Engineering, Chandigarh University, Sahibzada Ajit Singh Nagar- \\ 140413; e-mail: tarun.23007@gmail.com
}

\begin{abstract}
Soil is the foundation material which supports the loads from the overlying structure. Many times, soil beneath the structure has weak geotechnical properties, which affects the stability of soil and hence failure of the structure occurs in the form of settlements and cracks. So it is advisable to improve the properties of weak soil by soil reinforcement or soil stabilization. Also the industrial wastes are major threats across the globe for the environment due to its disposal problem and plastic waste is one of them. In the present study, therefore we have investigated the influence of waste polypropylene fibers on the resilient modulus ofclay soil. Under this investigation, several cyclic CBR tests were performed on soil specimens by reinforcing the clay soil with polypropylene fibers which were added in different percentages i.e. $0.3 \%, 0.4 \%, 0.5 \%, 0.6 \%$ by weight of soil. The outcomes show that the experimented technique is very effective to improve the resilient modulus of clay soil. It is found that for the best results, optimum percentage of waste polypropylene fibers to be added is $0.4 \%$ by weight of soil. Finally, it has been concluded that reinforcing the clay soil with polypropylene fibers provides positive influence on resilient modulus of the soil.
\end{abstract}

Keywords- Polypropylene Fibers, Resilient Modulus, Waste Plastic, Soil Reinforcement, Cyclic CBR, Clay Soil reinforcement is similar to the randomly distributed

\section{INTRODUCTION}

\subsection{Soil}

Different field of study has many different meaning of soil. On the basis on particle size and relative proportion of primary and secondary minerals based on their size, general structure and composition, we designated the soil. So being a geotechnical engineer, analysis of engineering response of different types of soil is especially important because all the structures will have to drift or founded on soil. Bearing capacity of soil also depends on various properties of soil. As the soft soils have low load bearing capacity thus weak soils like clay, silt etc are not perfect to build structures on them. So to improve these weaknesses a binding material is added to the soil to enhance its properties. This method of mixing additives to the soil to improve or overcome the weaknesses is known as soil stabilization. Soil stabilization used to be done with lime, cement, bitumen or with various chemicals but in this investigation we used Polypropylene Fiber with clay soil and checked its influence on Resilient modulus of the soil.

\subsection{Polypropylene Fibers}

For strength improvement of soil, randomly distribution of fibers is not a new technique. It has been used from very old time but the potential use of fiber reinforced soil was not frequent because of lack of understanding of reinforcing mechanism of fibers in soil fiber reinforcement. Different types of fibers like natural fiber and synthetic fibers are available as option for reinforcement. Utilization of PP-fibers as fiber [3]. We are looking at two major problems for any civil engineer and environment here, first is geotechnical problem i.e., the construction of any structure on weak soil and second is environmental problem i.e., disposal of industrial waste. [1] The use of PP-fibers as soil reinforcing material represents the solution for these two problems[12]. The wastes we are using to solve the problems are waste Polypropylene fibers from plastic chairs. The disposal of these wastes requires a large land area and taking over open lands for disposal in India is less possible due to high population density. The growing quantities of these wastes is a matter of great concern and as such increases the interests of researchers for their effective utilization [13].

\subsection{Resilient Modulus}

Resilient modulus has been initiated as a technique of identifying the elastic properties of pavement materials. It is expressed as the relationship of deviator stress applied to the pavement layers (and soil subgrade) and the resilient axial deformation convalesces after release of the deviator stress [10]. Empirical relations attempt to relate the resilient modulus to some type of soil parameter, such as bearing ratio (CBR), or resistance index (R-value) [7]. A fundamental problem with empirical relations is the models seek to assign a fixed value of resilient modulus to a given type of soil. Although, the value of resilient modulus is stress-strain dependent that is, the value changes as stress and strain conditions change. Many state transportation agencies have used, or continue to use, empirical pavement design methods 


\section{Available online at www.ijrat.org}

involving soil support values, California Bearing Ratio (CBR), or R-values [2]. The test measures the stiffness of a cylindrical specimen of sub grade soil that is subjected to a cyclic or repeated axial load [9]. For a given deviator stress, the resilient modulus, $\mathbf{M}_{R}$, is defined as the slope of the deviator-axial strain curve [8], or simply the ratio of the amplitude of the repeated axial stress to the amplitude of the resultant recoverable axial strain.

\section{RESULTS AND DISCUSSIONS}

Following experiments were performed to investigate the properties of soil and resilient modulus of soil.

1) Specific gravity test

2) Liquid limit test

3) Determination of grain size distribution

4) Standard proctor test

5) Cyclic CBR test

\subsection{Specific Gravity using Pycnometer:-}

The specific gravity was determined by Pycnometer method. The knowledge of specific gravity is needed in calculation of soil properties like void ratio, degree of saturation, etc.

Table 1. Specific Gravity by Pycnometer Method

\begin{tabular}{|l|c|c|c|}
\hline \multicolumn{1}{|c|}{ Sample Number } & $\mathbf{1}$ & $\mathbf{2}$ & $\mathbf{3}$ \\
\hline Wt. of Pycnometer (W1 gm) & 626 & 626 & 614 \\
\hline W1 + soil (W2 gm) & 726 & 726 & 714 \\
\hline W2 + water (W3gm) & 1512 & 1510 & 1530 \\
\hline W1 + water (W4 gm) & 1448 & 1448 & 1467 \\
\hline Specific gravity & $\mathbf{2 . 7 7}$ & $\mathbf{2 . 6 3}$ & $\mathbf{2 . 7 0}$ \\
\hline
\end{tabular}

Average value of Specific gravity $(G)=2.70$

\subsection{Liquid Limit Test:-}

Casagrande's apparatus was used for determination of liquid limit. At the bottom, a groove of size $2 \mathrm{~mm}$ wide, $8 \mathrm{~mm}$ high and $11 \mathrm{~mm}$ wide is made with the help of Casagrande's tool. For three identical samples, the number of blows is noted down for a groove to come in contact. Graph is plotted between water content on $\mathrm{Y}$ axis and corresponding number of blows on $\mathrm{X}$ axis. Liquid limit is the water content corresponding to 25 blows from the graph. Following flow curve was obtained.

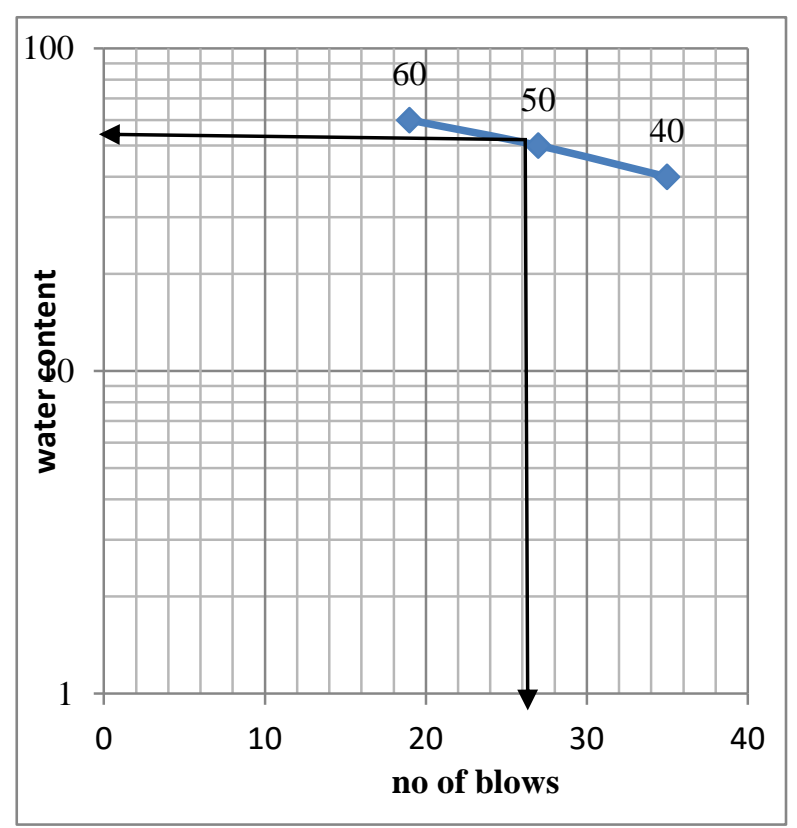

Fig. 1. Water Content v/s Number of Blows

Liquid limit from graph as shown in Fig. $1=53 \%$

\subsection{Grain Size Distribution:-}

For Particle distribution analysis, D10, D30, and D60 was calculated which represents a size in $\mathrm{mm}$ such that $10 \%, 30 \%$ and $60 \%$ of particles respectively are finer than that size. Thereafter, value of Coefficient of uniformity, $\mathrm{C}_{\mathrm{u}}$ and Coefficient of curvature, $\mathrm{C}_{\mathrm{c}}$ was determined by taking values of D10, D30 and D60 from graph as shown in Fig. 2.

$$
\begin{aligned}
& \text { D60 }=2.8 \mathrm{~mm} \\
& \text { D10 }=180 \text { microns } \\
& \text { D30 }=730 \text { microns }
\end{aligned}
$$

Coefficient of Curvature $=1.06$

Coefficient of Uniformity $=15.5$ 


\section{Available online at www.ijrat.org}

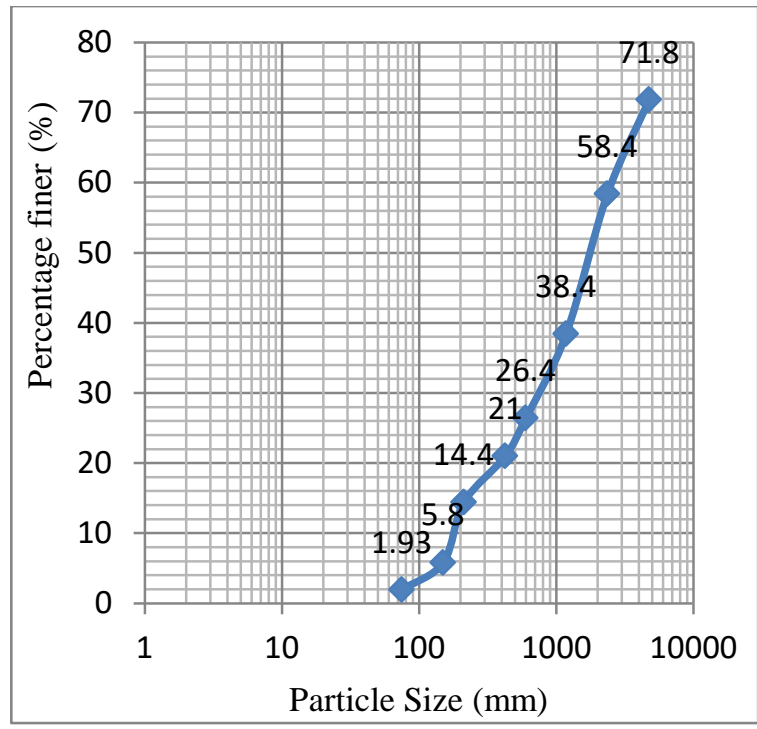

Fig. 2. Grain Size Distribution Curve

\subsection{Standard Proctor Compaction Test:-}

Standard Proctor Compaction test was performed on soil to determine maximum dry density and optimum moisture content as shown in Fig. 3.

From there, we get

Maximum dry density $=1.83 \mathrm{~g} / \mathrm{cc}$

Optimum Moisture Content $=14.23 \%$

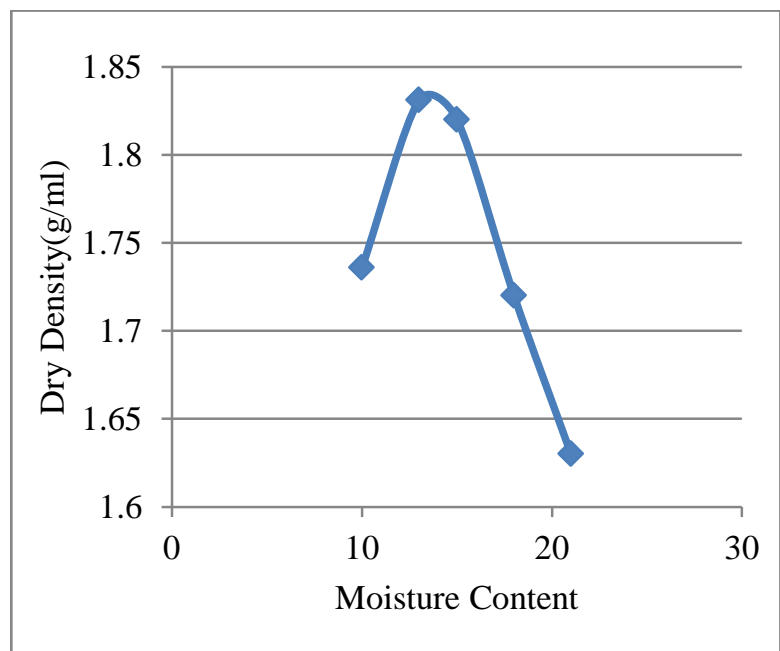

Fig. 3. Dry Density v/s Moisture Content of soil

\subsection{Cyclic CBR Test:-}

Principle of Cyclic California Bearing Ratio test is to use common CBR apparatus and perform number of cycles with respect to CBR test basics. In the absence of resilient modulus testing devices, the 1986 AASHTO Guide [11] suggested the following relationship between $\mathrm{Mr}$ and $\mathrm{CBR}$, or the California Bearing Ratio, (after Heuklelom and Klomp, 1962): $\mathrm{Mr}=1500(\mathrm{CBR})(\mathrm{psi})$

Table 2. Cyclic CBR for Soil reinforced with Polypropylene Fiber

\begin{tabular}{|c|c|c|}
\hline $\begin{array}{c}\text { Cyclic } \\
\text { CBR } \\
\text { Sample }\end{array}$ & $\begin{array}{c}\text { \%age of Polypropylene } \\
\text { Fiber added by weight } \\
\text { of soil }\end{array}$ & $\begin{array}{c}\text { Resilient } \\
\text { Modulus } \\
\text { (mpa) }\end{array}$ \\
\hline S1 & $0 \%$ & 85.42 \\
\hline S2 & $0.3 \%$ & 180.57 \\
\hline S3 & $0.4 \%$ & 204.77 \\
\hline S4 & $0.5 \%$ & 168.56 \\
\hline S5 & $0.6 \%$ & 156.27 \\
\hline
\end{tabular}

1) S1 i.e.0\% Polypropylene Fiber (Fig. 4.)

$\mathrm{CBR}$ value $=8.26$

$\mathrm{Mr}=1500 * 8.26=12,390 \mathrm{psi}=85.42 \mathrm{mpa}$

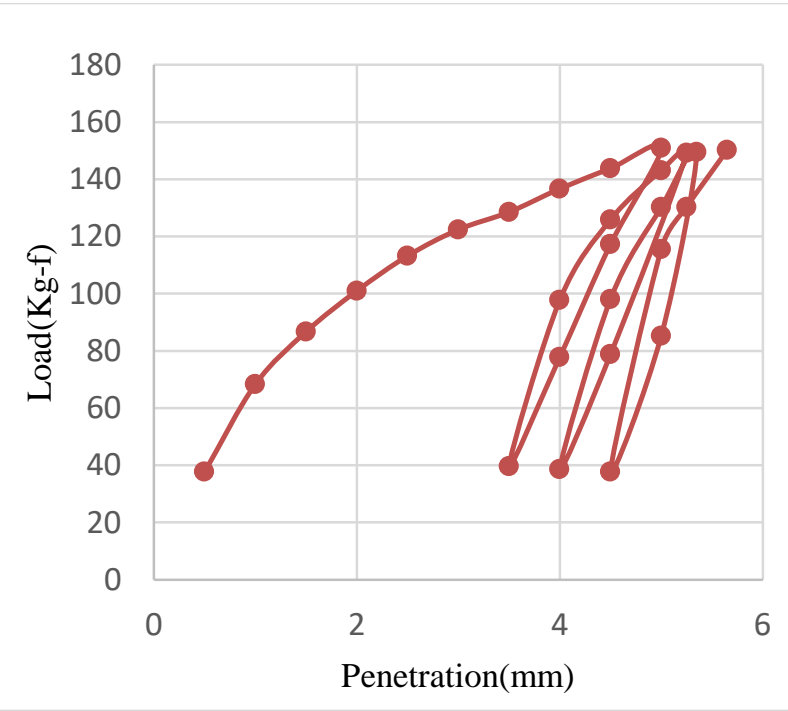

Fig. 4. Variation in Penetration (in $\mathrm{mm}$ ) for unstabilised soil

2) S2 i.e. 0.3\% Polypropylene Fiber (Fig. 5.)

$\mathrm{CBR}=17.46$

$\mathrm{Mr}=1500 * 17.46=26190 \mathrm{psi}=180.57 \mathrm{mpa}$ 


\section{Available online at www.ijrat.org}

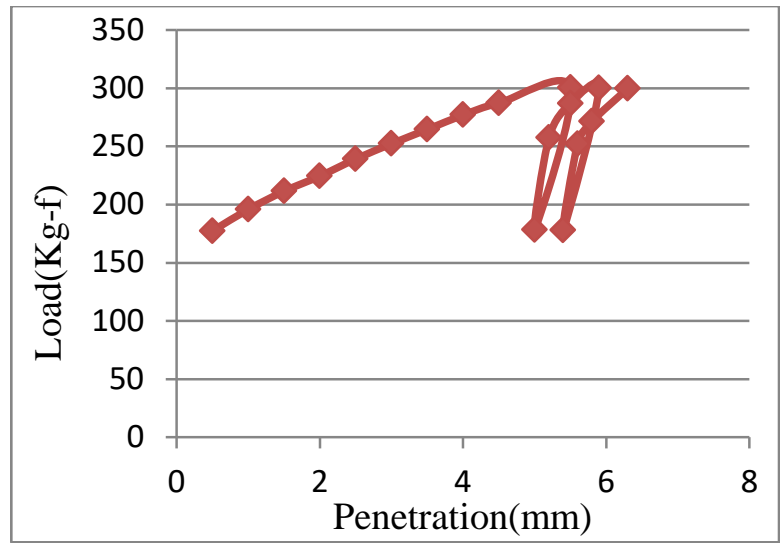

Fig. 5. Variation in Penetration (in $\mathrm{mm}$ ) for soil reinforced with $0.3 \%$ Fiber

3) S3 i.e. 0.4\% Polypropylene Fiber (Fig. 6.)

$\mathrm{CBR}=19.8$

$\mathrm{Mr}=1500 * 19.8=29,700 \mathrm{psi}=204.77 \mathrm{mpa}$

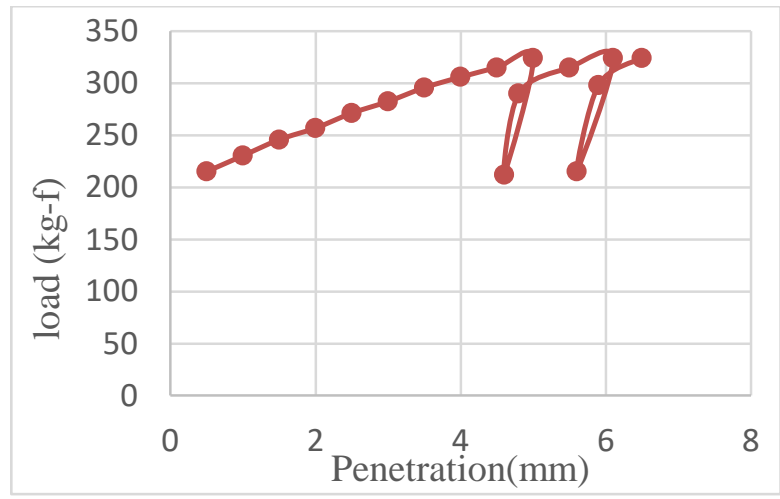

Fig. 6. Variation in Penetration (in $\mathrm{mm}$ ) for soil reinforced with $0.4 \%$ Fiber

4) S4 i.e. $0.5 \%$ Polypropylene Fiber (Fig. 7.)

$\mathrm{CBR}=16.2$

$\mathrm{Mr}=1500 * 16.2=24,448 \mathrm{psi}=168.56 \mathrm{mpa}$

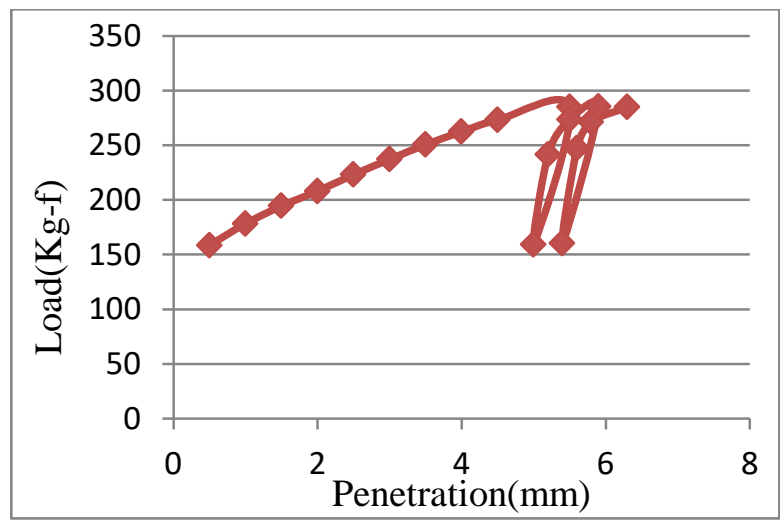

Fig. 7. Variation in Penetration (in $\mathrm{mm}$ ) for soil reinforced with $0.5 \%$ Fiber

5) S5 i.e. 0.6\% Polypropylene Fiber (Fig. 8.)
$\mathrm{CBR}=15.11$

$\mathrm{Mr}=1500 * 15.11=22,665 \mathrm{psi}=156.27 \mathrm{mpa}$

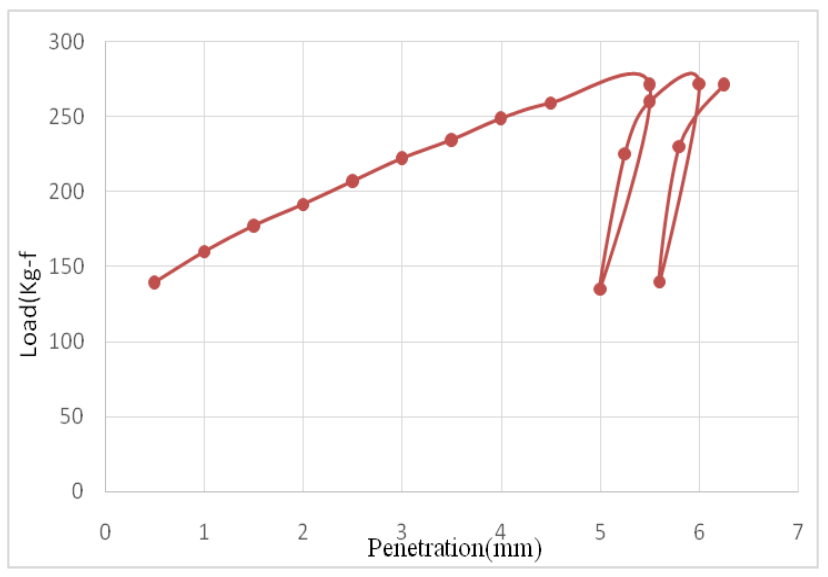

Fig. 8. Variation in Penetration (in $\mathrm{mm}$ ) for soil reinforced with $0.6 \%$ Fiber

\section{CONCLUSION}

From these results we conclude that the values of resilient modulus increase with the increase in $\%$ by weight of Polypropylene fiber added. At $0.4 \%$ of fiber addition, we obtained peak value of Mr.CBR value corresponding to $2.5 \mathrm{~mm}$ used against standard load of $1370 \mathrm{~kg}$ for calculation of CBR value. Further analysis on $0.5 \%$ and $0.6 \%$ of fiber addition was also performed to determine optimum fiber content to be added in order to attain maximum value of resilient modulus corresponding to percentage of fiber added.

\section{REFERENCES}

[1] Muntohar, A.S. (2009): "Influence of Plastic waste fibers on the strength of Lime-Rice Husk ash stabilised clay soil" Civil Engineering Dimension, Vol. 11, No. 1, p 3240.

[2] C.Rajakumar, Dr.T.Meenambal (2015): "CBR and UCC Strength Characteristics of Expansive Soil Subgrade Stabilized with Industrial and Agricultural Wastes" International Journal of ChemTech Research.

[3] Al-Refeai, T. (1991): "Behavior of granular soils reinforced with discrete randomly oriented inclusions" Geotextiles and Geomembranes, pp 319 - 333.

[4] Annals of Warsaw University of Life Sciences - SGGW Land Reclamation No 44 (2), 2012: 143-153(Ann. Warsaw Univ. of 
Life Sci. - SGGW, Land Reclaim. 44 (2), 2012)

[5] XVI ECSMGE Geotechnical Engineering for Infrastructure and Development, Edinburgh 2015, At 13-17 September 2015 - Edinburgh, Scotland, Volume: Vol 7, page $3747-3752$.

[6] D Kumar Choudhary Int. Journal of Engineering Research and Applications ISSN : 2248-9622, Vol. 4, Issue 6( Version 5), June 2014, pp.239-253

[7] Repeated load CBR testing, a simple but effective tool for the characterization of fine soils and unbound materials, A.A.A. Molenaar, Professor of Highway Engineering Faculty of Civil Engineering and Geo Sciences, Delft University of Technology P.O. Box 5048, 2600 GA Delft, the Netherlands

[8] Sas W., Gluchowski A., 2012. Methods of determination of the modulus of elasticity ( $\mathrm{E}$ and $\mathrm{Mr}$ ) from the repeated loading tests CBR. 21 (3), 171-181.

[9] ASTM Designation D1883, 2007. "Standard Test Method for CBR (California Bearing Ratio) of Laboratory". Compacted Soils, PP 2-3.

[10] Roy, T.K, Chattapadhyay, B. C and Roy, S. K. 2010. "California Bearing Ratio Evaluation and Estimation": A Study of Comparison, (Indian Geotechnical conference) IGC-2010, IIT, Mumbai, pp 1922.

[11] AASHTOT307-99, Standard Method of Test for Determining the Resilient Modulus of Soils and Aggregate Materials, American Association of State Highway and Transportation Officials, Washington, DC, USA, 2000.

[12] Akshaya Kumar Sabat, Subasis Pati and B.G. Mohapatro (2010) "Effect of Fiber on Properties of Rice Husk Ash - Lime Stabilised Soil" Indian Geotechnical Conference- 2010 Mumbai chapter. p 373376

[13] Yetimoglu, T., Salbas, O.(2003): "A study on shear strength of sands reinforced with randomly distributed discrete fibers"Geotextiles and Geomembranes, pp 103-110. 